chất cùng với việc dành thời gian quá nhiều vào việc sử dụng điện thoại thông minh có thể là nguyên nhân chính làm cho sinh viên nghiện điên thoại thông minh có tần suất tâp thể dục thể thao thấp hơn so với những sinh viên còn lại.

Số lượng sinh viên nghiện điện thoại thông minh có tỷ lệ làm thêm với tần suất "không bao giờ" và "thỉnh thoảng" cũng cao hơn so với sinh viên không bị nghiện điện thoại thông minh. Kết quả này phù hợp với báo cáo gần đây cho thấy sinh viên nghiện điện thoại thông minh dành quá nhiều thời gian cho việc sử dụng điện thoại, ảnh hưởng tới việc mất tập trung, không đạt được kết quả cao trong công việc. Mặt khác, điện thoại thông minh với các tín hiệu âm thanh và hình ảnh của chúng cảnh báo chủ sở hữu về các tin nhắn đến từ mạng xã hội, làm gián đoạn luồng suy nghĩ, tác động tiêu cực liên quan đến năng suất trong quá trình lao động. Những tác động trên dẫn đến tần suất và năng suất lao động giảm, vì vậy làm gián đoạn tham gia công việc làm thêm của sinh viên nghiện điện thoại thông minh.

\section{KẾT LUÂ̂N}

Trong số 1314 sinh viên năm 2-4 tại 36 trường đại học trên địa bàn thành phố Hà Nội, số sinh viên nữ sử dụng điện thoại thông minh nhiều hơn nam $(71,61 \%)$. Tỷ lệ sinh viên nghiện sử dụng điện thoại thông minh là $55,56 \%$. Lứa tuổi sinh viên sử dụng điện thoại thông minh chiếm tỷ lệ cao là 18-21 tuổi. Các ứng dụng sinh viên dùng phổ biến nhất trên điện thoại thông minh là Facebook và Facebook Messenger. Số lượng sinh viên nghiện điện thoại thông minh có tần suất tham gia thể dục thể thao và công việc làm thêm đều thấp hơn so với những sinh viển khác. Kết quả nghiên cứu này bước đầu cho thấy một số khía cạnh xã hội học của nghiện điện thoại thông minh ở sinh viên trên địa bàn Hà Nội là một thực trạng đáng lo ngại, là dấu hiệu cảnh báo cần thiết để xem xét các biện pháp nghiên cứu và can thiệp ở cấp độ rộng hơn.

TÀI LIẸU THAM KHẢO

1. Elhai JD, Dvorak RD, Levine, Hall, BJ, et al. (2017) "Problematic smartphone use: A conceptual overview and systematic review of relations with anxiety and depression psychopathology". Journal of Affective Disorders. 1(207): 251-259.

2. Kwon M, Kim DJ, Yang S, et al. (2013) "The Smartphone Addiction Scale: Development and validation of a short version for adolescents". PLoS One. 8(12): e83558.

3. APPOTA Technology for Change. Vietnam Mobile APP Market Report First half of 2018.
Available

https://appota.com/uploads/report/Vietnam_mobil e_app_market_Report_2018_EN.pdf $>$.

4. Lopez-Fernandez 0. (2017) "Short version of the Smartphone Addiction Scale adapted to Spanish and French: Towards a cross-cultural research in problematic mobile phone use". Addictive Behaviors. 64: 275-280.

5. Haug S, Castro RP, Schaub MP, et al. (2015) "Smartphone use and smartphone addiction among young people in Switzerland". Journal of Behavioral Addictions. 4(4): 299-307.

6. Hwang KH, Yoo YS, Cho OH. (2012) "Smartphone overuse and upper extremity pain, axiety, depression, and interpersonal relationships among college students". Journal of the Korea Contents Association, 12(10): 365-37.

7. Geser H. (2006) "Are girls (even) more addicted? Some gender patterns of cell phone usage". Sociology in Switzerland: Sociology of the Mobile Phone.

8. Luk TT, Wang MP, Shen $C$, et al. (2018) "Short version of the Smartphone Addiction Scale in Chinese adults: Psychometric properties, sociodemographic, and health behavioral correlates". Journal of Behavioral Addictions. 7(4): 1157-1165.

\title{
ĐÁNH GIÁ CẢM GIÁC ĐAU VÀ NHẠY CẢM SAU ĐIỀU TRI CHE TỦY TRỰC TIẾP VỚI VẬT LIỆU SINH HỌC CALCIUM SILICATE
}

\section{TÓM TẮT}

Mục tiêu: Mục tiêu nghiên cứu là đánh giá cảm giác đảau và nhạy cảm sau khi che tủy trực tiếp với

${ }^{1}$ Đai Hoc Y Dướ TP.HCM

Chịu trách nhiếm chính: Bùi Huỳnh Anh

Email: buihuynhanh@ump.edu.vn

Ngày nhân bài: 2/3/2021

Ngày phản biên khoa hoc: 1/4/2021

Ngày duyệt bài: 29/4/2021
Bùi Huỳnh Anh', Phạm Văn Khoa'

Mineral Trioxide Aggregate và Biodentine. Phương pháp: Thử nghiệm lâmm sàng với hai nhóm nghiên cứu đặt thuốc che tủy trực tiếp với Mineral Trioxide Aggregate và Biodentinetrên 22 răng cối nhỏ nguyên vẹn có chỉ định nhổ vì lý do chỉnh hình răng mặt ở các bệnh nhân từ 18-35 tuổi. Đánh giá cảm giác nhạy cảm hay đau sau điều trị sau 1, 7, 30 ngày với bảng câu hỏi và khám lâm sàng. Kêtt quả: Về cường độ và tỷ lệ đau, $64 \%$ nhóm MTA và $46 \%$ nhóm $B D$ bệnh nhân mô tả hiện tượng đau nhẹ và vừa. Về tổng thời gian đau, nhóm MTA có $29 \%$ trường hợp đau trong 1 ngày 
đầu, $43 \%$ trường hợp đau 1 tuần và $29 \%$ trường hợp đau 1 tháng; nhóm $\mathrm{BD}$ có $33 \%$ trường hợp đau 1 tuần và $67 \%$ trường hợp đau 1 tháng. Các cơn đau đều ngắn dưới 10 giây, đa số đau khi có tác nhân kích thích và không đau khi gõ. Sự khác biệt giữa hai nhóm nghiên cứu không có ý nghĩa thống kê $(p>0.5)$. Không có hiện tượng viêm hay chết tủy sau điều trị. Kết luâan: Sau điều trị che tủy trực tiếp với MTA và $\mathrm{BD}$, bệnh nhân có cảm giác nhạy cảm hoặc ê buốt nhưng không kéo dài và đa số ở mức nhẹ và vừa. Mineral Trioxide Aggregate và Biodentine cho kết quả không có sự khác biệt có ý nghĩa về cảm giác đau hay nhạy cảm sau điều trị che tủy trực tiếp. Ngoài ra, khả năng bảo tồn tủy sống tốt cho thấy hiệu quả trong điều trị nội nha bảo tồn của các vật liệu sinh học calcium silicate.

Từ khóa: Nội nha bảo tồn tủy,che tủy trực tiếp, vật liệu sinh học Calcium silicate, Mineral Trioxide Aggregate MTA, Biodentine, đánh giá đau.

\section{SUMMARY}

\section{EVALUATION OF PAIN RESPONSE AFTER DIRECT PULP CAPPING WITH CALCIUM-} SILICATE-BASED BIOMATERIALS

Objectives: The aim of was to evaluate ofpain or sensitive response afterdirect pulp capping with Mineral Trioxide Aggregateand Biodentine. Methods: This randomized clinical trial sudy was set up with direct pulp capping procedure with Mineral Trioxide Aggregate and Biodentine. The sample consisted of twenty-two caries-free, intact, permanent premolars, collected from 18 to 35 year-old humans and scheduled for extraction for orthodontic reasons. Postoperative pain was recorded by using VASWongBaker faces pain rating scale and percussion test responses up to one, seven and thirty days following the treatment. Results: Forincidence and intensity of postoperative pain, there was $64 \%$ of patientsin MTA group and $46 \%$ of patients in Biodentine group,experiencedmild and moderate painfollowing the procedure. For occurrence and total time of postoperative pain, pain response in MTA group after one, seven and thirtydays was $29 \%, 43 \%$, 29\%, respectively; in BD group pain response was occuredin $33 \%$ of patientsafterseven daysand $67 \%$ of patientsafter thirty days.For the lasting pain, all pain response persisted no longer than 10 seconds. Morover, patient usually felt pain with thermal stimulant and they feltno pain with percussion test. There was no significant difference in postoperative pain between the teeth that received either MTA or Biodentine $(p>0.5)$. There was no signs of pulpitis and all teeth remains their pulp vitality in recall clinical examination after direct pulp cappingtreatment. Conclusion: The findings of the present study showed that a majority of the patient reported pain following direct pulp cappingplacement, the pain responses was not prolonged and ranges from mild to moderate. There was no significant difference in pain reported between MTA or Biodentinewhen they were used as pulp capping agents. The overall survival ofpulp vitality shown the effective of calcium-silicate-based biomaterials in conservative endodontic treament.
Keywords: Vital pulp therapy, direct pulp capping, Calcium-Silicate-Based Biomaterials, Mineral Trioxide Aggregate (MTA), Biodentine, Pain Measurement.

\section{I. ĐẶT VẤN ĐỀ}

Những cảm giác không thoải mái, khó chiu, nhạy cảm hay đau trong điều trị nội nha nói chung và điều trị che tủy nói riêng thường xuất phát từ các nguyên nhân như viêm nhiễm, đáp ứng của tủy đối với vật liệu hay do thủ thuật lâm sàng sẽ ảnh hưởng mạnh đến tâm lý ngại điều trị của bệnh nhân và dẫn đến hiện tượng giảm ngưỡng chịu đau thực thể và gây ra thất bại điều trị. Vì vậy việc lựa chọn sử dụng vật liệu thích hợp và kiểm soát viêm nhiễm khi điều trị sẽ giúp bệnh nhân có được những trải nghiệm và trạng thái tâm lý tốt khi tiếp nhận điều trị.

Duy trì sự sống cho các răng đã bị tổn thương do chấn thương hoặc sâu răng là một trong mục tiêu quan trọng nhất của điều trị nội nha bảo tồn. Điêu trị che tủy trực tiếp là quy trình đặt các vật liệu tương hợp sinh học tại vị trí mô tủy lộ để bịt kín vùng phơi nhiễm và có tác dung như môt rào cản, đông thời, nó bảo vệ phức hợp ngà-tủy chống kích thích hóa học gây ra do các thủ thuật nha khoa, do độc tính và sự xâm nhập của vi khuẩn qua vi kẽ, đồng thời kích hoạt các phản ứng sữa chữa ngà tủy.và do đó, bảo tồn sự sống tủy. Các đặc điểm cơ bản của các vật liệu này là tính tương hợp sinh học, khả năng kháng khuẩn và lành thương mô, tương hợp tế bào; và khả năng dán kín tổn thương. Bền canhh đó, sự hình thành mô khoáng hóa bởi các tế bào tủy là chức năng chủ yếu của vật liệu sinh học được mong chờ trong liệu pháp điều trị này. Vì thế, mục tiêu của che tủy trực tiếp là tao phản ứng biệt hóa của các tế bào dạng nguyển bào ngà và sau đó chế tiết ngà trong vùng tiếp xúc, từ đó tái tổ chức lại cấu trúc mô ngà tủy tạo lành thương và giảm đau.

Hiện nay, các vật liẹu sinh học Calciumsilicate như chất khoáng trioxid tổng hợp (Mineral Trioxide Aggregate - MTA) và Biodentine (BD) được khuyến khích chỉ định nhiều trong điều trị tổn thương tủy, hướng dẫn lành thương. kích thích sự hình thành cầu ngà nhanh [2]. MTA là một vật liệu sứ sinh học có hoat tính sinh học, tương hợp sinh hoc, kháng khuẩn với đô ổn định và khả năng khít sát cao[6].MTA cũng có tác dụng tốt trong việc kiểm soát quá trình viêm. Vật liệu BDcó ưu điểm về đă̆c tính cơ hoc gần tương tự ngà, được sử dung như một chất thay thế ngà thân và chân răng [4], kháng khuẩn và có tác động tốt trên các tế bào tủy và kích thích sự hình thành ngà sửa chữa [7]. 
Nhiều báo cáo nghiên cứu đã chứng minh hiệu quả đáng kể trong thủ thuật che tủy trực tiếp bằng MTA và $B D$, mang lại tỷ lệ thành công cao cả trong invitro trên tế bào, trên động vật và trong thử nghiệm invivo lâm sàng ở người với tỷ lệ trung bình $81-100 \%$ cho cả $M T A$ và $B D[2]$.

Các thử nghiệm lâm sàng trên sâu ngà sâu có tiếp xúc với tủy được che tủy trực tiếp hoặc lây tủy buồng với $M T A$ và $B D$ và cho thấy tỷ lệ thành công cao (80-100\%) ở cả răng vĩnh viễn chưa đóng chópvà đã đóng chóp[3] trong nhiều khoảng thời gian từ sáu tháng[3], 12 tháng [2], 18 tháng, đến ba năm [1].

Tại Việt Nam hiện nay các nghiên cứu về vật liệu sinh học vẫn còn khá ít và chưa có các minh chứng thuyết phục cho hiệu quả của vật liệu, do vậy mục tiêu của nghiên cứu này là mô tả và đánh giá các đặc điểm về cảm giác đau hay nhạy cảm của bệnh nhân trong điều trị che tủy trực tiếp trên răng vĩnh viễn với MTA và BD.

II. ĐỐI TƯợNG VÀ PHƯƠNG PHÁP NGHIÊN CỨU

2.1. Thiết kế nghiên cứu: Thử nghiệm lâm sàng ngẫu nhiên theo mô hình nghiên cứu với hai nhóm nghiên cứu che tủy trực tiếp với hai loại vật liệu MTA và BD.

2.2. Đối tượng nghiên cứu: Độ tuổi từ 1835 tuổi, là sinh viên hoặc bệnh nhân khám Răng Hàm Mặt tại Đại học Y Dược thành phố TP. Hồ Chí Minh (TPHCM)

2.3. Thời gian nghiên cứu: từ tháng 6/2019- tháng2/2021.

Cỡ mẫu và chọn mẫu: Sử dụng phương pháp chọn mẫu thuận tiện là các hồ sơ khám và bốc thăm ngẫu nhiển để chọn vào nghiên cứu. Mẫu nghiên cứu là 22 răng cối nhỏ, mỗi nhóm nghiên cứu có 11 răng.

2.4. Tiêu chuẩn chọn mẫu:

-Bệnh nhân có răng cối nhỏ vĩnh viễn hàm trên hoặc hàm dưới cần nhổ vì lý do chỉnh hình thông thường.

-Răng có tổn thương ở mức độ 0-3: theo thang ICDAS II 2009).

-Bệnh nhân tự nguyện tham gia nghiên cứu.

-Không có tiền sử chấn thương.

-Không có đau tự phát hoặc đau liên tục.

-Các triệu chứng lâm sàng và thử tủy nhiệt và thử điện tương ứng với tủy bình thường.

-Biểu hiện trên phim $X$ quang: không có sang thương thấu quang quanh chóp, răng đã đóng chóp hoàn toàn.

-Bệnh nhân không có vấn đề về sức khỏe toàn thân ảnh hưởng đến quá trình lành thương.

\subsection{Vấn đề y đức}

- Mẫu là những người tình nguyện tham gia nghiên cứu, được nghiên cứu viên giải thích trực tiếp về cơ chế, quy trình điều trị, nguy cơ của phương pháp nội nha bảo tồn tủy bằng điều trị che tủy trực tiếp, các biến chứng hay cảm giác nhạy cảm có thể gặp và các điều trị thay thể.Bệnh nhân đồng ý tiếp nhận gây tê và chụp $X$ quang khi điều trị và sử dụng thuốc kháng sinh, kháng viêm, giảm đau nếu cần thiết.

-Kết quả nghiên cứu nhằm phục vụ cho mục đích y học, không nhằm mục đích khác.

- Nghiên cứu đã được Hội đồng đạo đức trong nghiên cứu y sinh trường Đại học Y dược TPHCM thông qua ngày $21 / 05 / 2019$.

2.6. Phương pháp đánh giá và thu thập số liệu: Phiếu tự đánh giá dành cho bệnh nhẩn được thiết kế theo Thang đo đau VAS (Visual Analog Scale) theo Wong-Baker (hình 1) và các câu hỏi đánh giá đặc điểm cơn đau qua mô tả tần suất, cường độ, thời gian và tác nhân kích thích của cơn đau. Trước khi tự đánh giá, BN đã được giải thích, hướng dẫn cặn kẽ về thang đo đau(từ 1-10 điểm) để $B N$ có thể tự thực hiện chính xác việc đánh giá điểm số mức độ đau hiện tại.

THANG ĐIËM ĐAU THEO WONG-BAKER

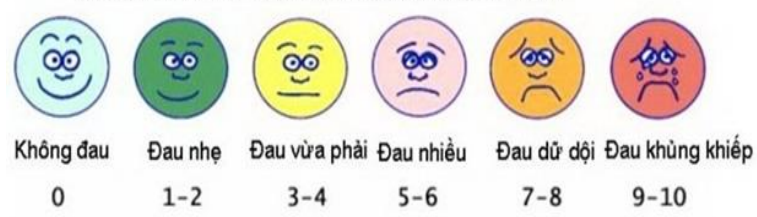

Hinh 1. Thang đo đau VAS.

Phiếu khám đánh giá được ghi nhận các tiêu chí lâm sàng trước và sau điều trị bao gồm:

- Cảm giác đau của bệnh nhân: cường độ, thời gian, tác nhân gây đau, kiểu đau...

- Thử nghiệm gõ răng: đau hay không đau.

- Thử nghiệm nhiệt: thử nóng và thử lạnh răng có đáp ứng hay không.

- Thử điện: răng có đáp ứng hay không, mức độ đáp ứng.

- Có sưng hay viêm ở vị trí chóp chân răng không, có/còn lỗ dò.

- Độ lung lay của răng, tình trạng nha chu.

Các tiêu chí đánh giá được xây dựng theo mã số mã số (1) hoặc (2) tương ứng với hai mức độ không hoặc mã số từ (1)-(4), với mã số (1) là mức độ mong muốn nhất và mã số (4) là mức độ không mong muốn nhất.

2.7. Quy trình nghiên cứu. Nghiên cứu viên thực hiện khám lâm sàng, hỏi và ghi nhận triệu chứng lâm sàng chủ quan: khó chịu, nhạy cảm, đau,.. và đánh giá sơ khởi triệu chứng thực 
thể: mức độ sâu răng nếu có, tình trang nha chu, tiên lượng phục hồi. Thử nghiệm gõ được thực hiện với đầu cán gương gõ trên mặt nhai, mặt ngoài, mặt trong của răng thử nghiệm, dùng sức vừa đủ để bênh nhân phân biêt được răng lành mạnh và răng bị viêm dây chẳng. Thử nghiệm sự sống tủy gồm thử lạnh và thử điện với máy điện cực Digitest ${ }^{\mathrm{TM}}$ II Pulp Vitality Tester (Parkell, Mỹ).Thử nghiệm luôn thực hiện lặp lại 3 lần với răng liên quan và răng chứng cùng tên hoặc răng lân cận có tủy lành mạnh bình thường.

Điều trị bắt đầu với gây tể tại chỗ $(1,8 \mathrm{ml}$, 2\% Lidocaine có 1:100.000 Epinephrine). Răng được cô lập răng với đê cao su, tạo xoang đặt vật liệusử dụng mũi khoan tròn kim cương $1 \mathrm{~mm}$ với tay khoan siêu tốc có nước phun sương tạo xoang loại I trên mặt nhai kích thước khoảng $2 \mathrm{~mm} \times 2 \mathrm{~mm}$, rửa xoang bằng dung dịch sát khuẩn $\mathrm{CHX} 2 \%$, đến khi lộ tủy, bơm rửa bằng dung dịch $\mathrm{NaOCl} 2.5 \%$. Đánh giá mức độ chảy máu bằng cách ép chặt viên gòn đã ngâm dung dịch sát khuẩn muối sinh lý $0,9 \%$ trong 10 phút, nếu có thể cầm máu được, sát khuẩn xoang trám với viên gòn tẩm dung dịch $\mathrm{NaOCl} 3 \%$ (Hyposol, Prevest, Chile).

Quy trình đặt thuốc che tủy trực tiếpđược thực hiện theo trình tự của phác đồ điều trị chuẩn che tủy trực tiếp theo Hướng dẫn của Hiêp hội Nội Nha Châu Âu (2006). Trôn MTA (Angelus, Mỹ) hoặc BD(Septodont, Pháp) theo hướng dẫn của nhà sản xuất thành dạng bột nhão đồng nhất. Sau đó đặt thuốc bằng bộ ống bơm chuyên dụng, dùng cây bay và nhồi để tạo hình lớp thuốc sao cho thành một lớp dày $2 \mathrm{~mm}$ che phủ phần tủy lộ và che phủ ra ngoài giới hạn tủy lộ $0,5-1 \mathrm{~mm}$ với kích thước toàn bộ lớp thuốc nằm trong khoảng ít hơn $2 \times 2 \mathrm{~mm}$. Đăt một miếng gòn ẩm mỏng lên trên lớp MTA và trám tạm bằng GIC Fuji IX (GC, Nhật), sau đó hẹn tái khám sau 1 tuân, tháo trám tạm, trám lót bằng GIC và trám hoàn tất bên ngoài bằng Composite G-aenial (GC, Nhật), mài chỉnh khớp cắn và đánh bóng hoàn tất miếng trám. Nghiên cứu viên khám lâm sàng miếng trám không sút, không sâu tái phát, răng không đổi màu, không chảy mủ, chảy dịch, không lỗ dò, thực hiện lại các thử nghiệm tủy (nhiệt và điện) và gõ.Các răng được chụp $X$ quang quanh chóp làm phim chẩn đoán ban đầu, trước và sau đặt thuốc che tủy, ghi nhận đặc điểm của ngà tủy, chân răng, vùng quanh chóp và dây chằng nha chu.Bệnh nhân được hướng dẫn các giải pháp chống nhạy cảm ngà hoặc ghi toa thuốc giảm đau, kháng viêm nếu cần thiết, sau đó điền bảng câu hỏi về triệu chứng nhạy cảm hoặc đau sau điều trị.

Buổi tái khám nhổ răng tuân thủ đúng theo chỉ định của kế hoạch điêu trị chỉnh nha (sau 612 tuần) và nhổ răng được thực hiện dưới gây tê tại chố với kỹ thuật nhổ răng không sang chấn bởi bác sĩ phẫu thuật miệng. Bệnh nhân hoàn thành các bảng câu hỏi để kết thúc nghiên cứu. Sau nhổ răng, bệnh nhân được hướng dẫn chăm sóc vùng nhổ răng theo quy trình chăm sóc hậu phẫu thường quy: kê toa thuốc giảm đau, tái khám ổ nhổ răng và theo dõi lành thương sau 1 tháng, hướng dẫn vệ sinh răng miệng.

2.8. Phân tích và xử lý thống kê. Các số liệu nghiên cứu thu thập từ bảng câu hỏi và phiếu khám được nhập liệu vào phần mềm STATA 14.

\section{KẾT QUẢ NGHIÊN CỨU VÀ BÀN LUÂ̂N}

3.1. Cường độ đau. Cường độ đau hay nhạy cảm của bệnh nhân được thể hiện trong bảng 1 ở các thời điểm sau đặt thuốc 1 ngày, 1 tuần và 1 tháng. Các mức độ của cường độ đau như sau: (1) không đau, (2): đau nhe và vừa phải (1-4 điểm); (3): đau nhiều (5-8 điểm); (4): đau rất nhiều (9-10 điểm). Thời điểm 24 giờ là khoảng thời gian đầu sau điều trị, mức độ đaucòn tương đối cao; có 7/11 (64\%) ca ở nhóm MTA và $5 / 11(46 \%)$ ca ở nhóm $B D$ mô tả hiện tượng đau nhe và vừa. Trong cả hai nhóm chỉcó 1 bệnh nhân báo cáo mức độ đau nhiều ở nhóm $\mathrm{BD}$ sau 1 ngày. Sau đó cơn đau giảm dần sau vài ngày và trở lại bình thường sau 1 tháng ở tất cả các đối tượng nghiên cứu.Sự khác biệt về cường độ đau giữa hai nhóm nghiên cứu không có ý nghĩa thống kê $(p>0.5)$. Điều tương tự cũng được ghi nhận ở báo cáo của Bokhari (2016) [8][8] về các cơn đau mức độ trung bình trong ngày đầu sau che tủy trực tiếp với MTA và $B D$.

Xét riêng nhóm MTA, sự thay đổi về mức độ đaugiữa hai thời điểm 1 ngày và 1 tuần không có sự khác biệt ( $p>0.5)$, tuy nhiên có sự khác biệt ý nghĩa về cảm giác đau giữa thời điểm 1 tháng sau điều trị và 1 ngày hay 1 tuần $(p<0.005)$. Xét riêng nhóm $B D$, sự thay đổi về mức độ đau không có sự khác biệt giữa ba thời điểm 1 ngày, 1 tuần và 1 tháng $(p>0.5)$.

Sự thay đổi về mức độ đau giữa bathời điểm ghi nhận trong nghiên cứu là 1 ngày, 1 tuần và 1 tháng giúp hình dung được mức độ giảm đau là nhiêu hay ít trong thời gian sau khi đặt thuốc.Giai đoạn đầu sau điều trị là khoảng thời gian khó chịu nhất với bệnh nhân vì cơ thể sinh ra một loạt các đáp ứng miễn dịch không đặc hiệu gây ra cơn đau. Do đó, việc lựa chọn vật 
liệu có khả năng bịt kín tủy lộ và ngăn ngừa sự xẩm nhập vi khuẩn được coi là yếu tố quan trọng nhất trong tránh và giảm thiểu viêm tủy.

Trong nghiên cứu, có mộtbệnh nhân nhóm $\mathrm{BD}$ cós ử dụng thuốc giảm đau sau đặt thuốc 1 tuần.Việc giảm mức độ đau nhiều trong giai đoạn đẩu có ý nghĩa lớn. Điều này giúp các bệnh nhẩn không cần sử dụng thêm thuốc giảm đau để cảm thấy dễ chịu. Khi xem xét thêm các nghiên cứu khác, khi bệnh nhân có cơn đau do viêm tủy trước điều trị, việc sử dụng vật liệu sinh học che tủy cho thấy sự giảm đau rõ rệt sau điêu trị [1][5].

3.2. Tổng thời gian đau. Tiêu chí này được chia thành các mức độ: (1): không đau; (2): Đau trong 1 ngày sau điều trị; (3): Đau trong 2-7 ngày; (4): Đau trong 8-30 ngày (Bảng 1 ).

Ơ nhóm MTA, trong 7 trường hợp đau thì 2 ca chỉ đau trong 1 ngày đầu (29\%), 3 ca kéo dài trong 1 tuần $(43 \%)$ và 2 ca kéo dài 1 tháng
(29\%). Ở nhóm BD, trong 6 trường hợp đau thì không có trường hợp nào chỉ đau trong ngày đầu mà kéo dài 1 tuần (2 ca-33\%) và 1 tháng (4 ca-67\%). Sự khác biệt giữa hai nhóm nghiên cứu không có ý nghĩa thống kê ( $p>0.5)$.

Ở 3/11 bệnh nhân nhóm $\mathrm{BD}$ có biểu hiện đau trong 1 ngày và kéo dài trong tháng đầu tiên có thể được giải thích làkhi hàm lượng tế bào viêm tăng lền,phản ứng viêm nhanh chóng xảy ra trong một không gian tủy răng tương đối lớn ở người trẻ với tuần hoàn dồi dàovà hiện tượng đau có thể đến nhanh và khá rõ, Tuy nhiên, các cơn đau được kiểm soát tốt với thuốc giảm đau và giảm dần sau 1 tuần-1 tháng. So với báo cáo có $2 / 12$ (nhóm $B D$ ) và $1 / 12$ (nhóm MTA) phàn nàn về cơn đau tự phát trong 3 tuần đâu và được điều trị tủy giảm đau trong báo cáo của Hegde (2017 [3]) được giải thích là do hiện tượng lành thương kém và thời gian sâu răng hay bộc lộ tủy có sự khác biệt giữa hai nghiên cứu.

Bảng 1. Cường độ đau trong các khoảng thời gian khác nhau.

\begin{tabular}{|c|c|c|c|c|c|c|c|c|c|}
\hline 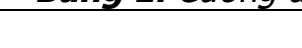 & \multicolumn{4}{|c|}{ MTA $(n=11)$} & \multicolumn{4}{|c|}{ BD $(n=11)$} & Giá trị p(*) \\
\hline & $(1)$ & $(2)$ & (3) & (4) & (1) & $(2)$ & (3) & (4) & \\
\hline 1 ngày & 4 & 7 & 0 & 0 & 5 & 5 & 1 & 0 & $p>0.5$ \\
\hline 1 tuần & 6 & 5 & 0 & 0 & 5 & 5 & 1 & 0 & $p>0.5$ \\
\hline 1 tháng & 11 & 0 & 0 & 0 & 10 & 1 & 0 & 0 & $p>0.5$ \\
\hline Tống thời gian đau & 4 & 2 & 3 & 2 & 5 & 0 & 2 & 4 & $p>0.5$ \\
\hline
\end{tabular}

(*)Kiếm định chính xác Fisher

3.3. Thời gian mối lân đau. Đánh giá thời gian mỗi lần đau gồm 4 mức độ:(1): Ngắn (0-10 giây); (2): Trung bình (10 giây - 1 phút); (3): Dài (2-10 phút); (4): Rất dài ( $>10$ phút); trong nghiên cứu, $100 \%$ ca chỉ cảm thấy cơn nhạy cảm hay đau thoáng qua ngắn dưới 10 giây. Hiện tượng đau thoáng qua này cũng được mô tả tương tự ở đa số bệnh nhân trong các thử nghiệm lâm sàng của Nowicka (2013)[5] và Hegde 2017 [3]. Cơn đau không gây khó chịu quá lâu, vì vậy hầu hết bệnh nhân trong nghiên cứu không cần sử dụng thuốc giảm đau hoặc uống trong 6 giờ đầu sau đặt thuốc.

\subsection{Tác nhân gây đau và kiểu đau}

Các mức độ ghi nhận như sau: - Tác nhân gây đau (1): Nhiệt độ nóng, lạnh; (2): Lực ăn nhai; (3): Tư thế: ngủ, nằm; (4): Tự phát, không có tác nhân.

- Kiểu đau: (1): Đau âm ỉ, ê ẩm; (2): Đau buốt; (3): Đau theo mạch đập; (4): Đau nhói kiểu dao đâm. Trường hợp nào không đau không được tính trong tiêu chí này.

Đa số bệnh nhân (5/7 ca ở nhóm MTA và 6/6 ca ở nhóm $\mathrm{BD}$ ) cảm thây nhạy cảm khi ăn hoặc uống thực phẩm nóng hay lạnh. Riêng nhóm MTA có 2 bệnh nhân mô tả cơn đau tự phát ngắn và thoảng qua. Kiểu đau được mố tả ở nhóm MTA là đau âm ỉ, hoặc đau ê buốt, còn nhóm $\mathrm{BD}$ thì bệnh nhân cho rằng đau ê buốt nhiều hơn (Bảng 2).

Bảng 2. Tác nhân gây đau và kiểu đau

\begin{tabular}{|c|c|c|c|c|c|c|c|c|c|}
\hline & \multicolumn{4}{|c|}{ MTA $(n=7)$} & \multicolumn{4}{|c|}{$B D(n=6)$} & Giá trị p (*) \\
\hline & (1) & (2) & (3) & (4) & (1) & (2) & (3) & (4) & \\
\hline Tác nhân ge & 4 & 1 & 0 & 2 & 6 & 0 & 0 & 0 & $p>0.1$ \\
\hline Kiếu đau & 3 & 4 & 0 & 0 & 0 & 6 & & & $\mathrm{D}>0.1$ \\
\hline
\end{tabular}

(*)Kiểm định chính xác Fisher

3.5. Cảm giác đau trong thử nghiệm gõ dọc. Mức độ đau khi gõ dọc phản ánh mức độ viêm dây chằng nha chu của răng. Đánh giá mức độ đau khi gõ dọc giúp nhận biết các tình trạng cẩp tính và xác định chính xác vị trí răng bị đau.

Chỉ có 3 trường hợp nhóm MTA và 1 trường hợp nhóm BD có cảm giác nhạy cảm rõ khi gõ dọc. 
Hầu hết các răng khác trong nghiên cứu (8/11 nhóm MTA và 10/11 nhóm BD) không thấy đau khi gõ dọc sau đặt thuốc. Vài bệnh nhân mô tả cảm giác lạ nhưng không đau (Bảng 3).

Bảng 3. Cảm giác đau trong thử nghiệm gõ dọc.

\begin{tabular}{|c|c|c|c|c|}
\hline & Mức độ & MTA (n=11) & BD(n=11) & Giá trị p (*) \\
\hline $\begin{array}{c}\text { Đau trong thử } \\
\text { nghiệm gõ }\end{array}$ & $\begin{array}{c}\text { (1): Gõ không đau } \\
\text { (2): Gõ đau }\end{array}$ & $\mathbf{8}$ & $\mathbf{1 0}$ & $\mathbf{p}>\mathbf{0 . 5}$ \\
\hline
\end{tabular}

$(*)$ Kiếm đinh chính xác Fisher

Thời điểm trước điều trị, không có răng nào của hai nhómđáp ứng đau khi gõ dọc thể hiện vùng dây chằng nha chu bình thường. Sau điều trị, mặc dù nhiểm trùng được loại bỏ do hiệu quả diệt khuẩn và tạo hàng rào bảo vê tốt của thuốc che tủy nhưng hiệu quả có thể không phải là hoàn toàn. Vì vậy tuy khả năng lành thương có thể khởi phát do dự giảm viêm nhiễm và hoạt tính sinh học của thuốc nhưng mức độ đáp ứng có thể phụ thuộc vào nhiêu yếu tố như: đặc tính thuốc, khả năng miễn dịch, lực cơ học tác động hay kích thích....Khi răng bị nhiễm trùng và có hiện tượng viêm dây chằng nha chu, cơn đau sẽ trở nên cụ thể với bệnh nhân. Do đó, răng bị ảnh hưởng sẽ dễ nhận biết bằng thử nghiệm gõ hơn là giai đoạn đầu mới có triệu chứng tủy.

Dưa trên kiến thức về tiềm năng tự sửa chữa mô tủy từ đó dẫn đến sự hình thành ngà thứ ba hay ngà sửa chữa dưới sự kích thích của các vật liệu sinh học. Nhiều tác giả ghi nhận rằng tủy có thể tạo thành một hàng rào mô cứng sau khi che tủy trực tiếp hoặc lấy tủy bán phần.Trong quá trình hình thành ngà sửa chữa, nguyên bào ngà nguyên thủy tại vị trí tiếp xúc kích thích bị phá hủy và được thay thế bằng tế bào giống như nguyên bào ngà mới biệt hóa. Quá trình lành thương tủy liên quan đến sự di cư của các tế bào gốc vào vị trí tổn thương, tăng sinh và biệt hóa thành các tế bào giống nguyên bào ngà, sau đó thực hiện chức năng tạo ngà sửa chữa và lành thương.

Biểu hiện lâm sàng của lành thương cũng là sự giảm cảm giác nhạy cảm, giảm ê buốt hay giảm đau, điều này là mối quan tâm hàng đầu đối với bệnh nhân. Vì vậy, tiềm năng thuốc đối với các tác động trên hệ thần kinh cảm giác là một đặc tính cần quan tâm của nhà lâm sàng khi lựa chọn vật liệu che tủy phù hợp giúp giảm đau nhanh và hiệu quả.

Tóm lại, trong nghiên cứu này, các răng không triệu chứng (không có dấu hiệu viêm tủy) ban đầu vẫn bảo tồn được sự sống của tủy và không có cảm giác khó chịu/đau hoặc chỉ xuất hiện cảm giác đau nhẹ và ngắn. Ngoài ra, khám lâm sàng không có ca nào sưng hay viêm ở vị trí chóp chân răng và không có lố dò; không có răng lung lay, tình trạng nha chu ổn định và không có dấu hiệu bệnh lý trên phim $X$ quang.
Toàn bộ các thử nghiêm sự sống tủy cũng cho kết quả dương tính. Điều này phản ánh hiệu quả sinh học tốt của MTA [6]và BD [7]trên phương diện bảo tồn mô tủy sống [4].

\section{KẾT LUẬN}

Những kết quả nghiên cứu lâm sàng trên góp phần cung cấp thêm minh chứng về tác động trên hệ thần kinh của vật liệu sinh học calciumsilicate dùng cho phương pháp điều trị nội nha bảo tồn tủy. MTA và $B D$ cũng cho kết quả không có sự khác biệt có ý nghĩa về cảm giác đau hay nhạy cảm sau điều trị che tủy trực tiếp. Điều này cho thấy đây là những vật liệu có hiệu quả lâm sàng tốtkhông thể thiếu trong bảo tồn và phục hồi sự sống tủy cho các răng vĩnh viễn có bị tổn thương tủy như một giải pháp an toàn, hiệu quả cao và là phương pháp can thiệp tối thiểu thích hợp thay thế các vật liệu hay can thiệp cũ có tính xâm lấn hơn.

\section{TÀI LIẸU THAM KHẢO}

1. Awawdeh L., Al-Qudah A., Hamouri H., et al. (2018), "Outcomes of Vital Pulp Therapy Using Mineral Trioxide Aggregate or Biodentine: A Prospective Randomized Clinical Trial", J Endod, 44 (11), pp. 1603-1609.

2. Brizuela $C_{.,}$Ormeno $A_{.}$, Cabrera $C_{.}$et al. (2017), "Direct Pulp Capping with Calcium Hydroxide, Mineral Trioxide Aggregate, and Biodentine in Permanent Young Teeth with Caries: A Randomized Clinical Trial", J Endod, 43 (11), pp. 1776-1780.

3. Hegde S., Sowmya B., Mathew S., et al. (2017), "Clinical evaluation of mineral trioxide aggregate and biodentine as direct pulp capping agents in carious teeth", J Conserv Dent, 20 (2), pp. 91-95.

4. Kaur M., Singh H., Dhillon J. S., et al. (2017), "MTA versus Biodentine: Review of Literature with a Comparative Analysis", Journal of clinical and diagnostic research : JCDR, 11 (8), pp. ZG01-ZG05.

5. Nowicka A., Lipski M., Parafíniuk M., et al. (2013), "Response of human dental pulp capped with biodentine and mineral trioxide aggregate", J Endod, 39 (6), pp. 743-7.

6. Parirokh M., Torabinejad M. (2010), "Mineral trioxide aggregate: a comprehensive literature review--Part I: chemical, physical, and antibacterial properties", J Endod, 36 (1), pp. 16-27.

7. Rajasekharan S., Martens L. C., Cauwels R., et al. (2018), "Biodentine material characteristics and clinical applications: a 3 year literature review and update", Eur Arch Paediatr Dent, 19 (1), pp. 1-22. 